\title{
Health Risks of Environmental Exposure to PCDD/Fs near a Hazardous Waste Incinerator in Catalonia, Spain
}

\author{
Montse Mari \\ Departament dôEnginyeria Quimica, Universitat Rovira i Virgili, Av. Països Catalans 26 \\ 43007 Tarragona, Catalonia, Spain \\ Jordi Díaz-Ferrero \\ Univ Ramon Llull, IQS Environmental Laboratory, Via Augusta 390 \\ 08017 Barcelona, Catalonia, Spain \\ Marta Schuhmacher \\ Departament dôEnginyeria Quimica, Universitat Rovira i Virgili, Av. Països Catalans 26 \\ 43007 Tarragona, Catalonia, Spain \\ Martí Nadal \\ Laboratory of Toxicology and Environmental Health, IISPV, Universitat Rovira i Virgili, Sant Llorenç 21 \\ 43201 Reus, Catalonia, Spain \\ José L. Domingo \\ Laboratory of Toxicology and Environmental Health, IISPV, Universitat Rovira i Virgili, Sant Llorenç 21 \\ 43201 Reus, Catalonia, Spain \\ E-mail: joseluis.domingo@urv.cat \\ Received 30 April 2013; accepted 28 June 2013

\begin{abstract}
In order to evaluate the environmental impact of a hazardous waste incinerator (HWI) located in Constantí (Spain), during the period 2010-2012, 30 vegetation and soil samples were alternatively (herbage in 2010 and 2012, and soils in 2011) collected in the surroundings of the facility, and their contents of polychlorinated dibenzo-p-dioxins and dibenzofurans (PCDD/Fs) determined. Data were compared with those of previous campaigns, and especially with PCDD/F levels in the same monitors reported in the baseline study (1998), when the facility was being constructed. In general terms, a continuous decrease of PCDD/Fs in soils was observed, while in herbage the results indicated an increase since 2008. Anyhow, the health risks associated to environmental exposure of PCDD/Fs are currently within acceptable ranges.
\end{abstract}

Keywords: hazardous waste incinerator, PCDD/Fs, soils, vegetation, health risk assessment, Constantí (Spain).

\section{Introduction}

Since 1999, the only hazardous waste incinerator (HWI) in Spain is operating in Constantí (Catalonia). Even more than other industrial facilities, waste incinerators generate a notable concern among the population living around, since they are potential sources of emission of a wide range of pollutants. Among these, incinerators have been traditionally catalogued as major sources of polychlorinated dibenzo- $p$-dioxins and dibenzofurans (PCDD/Fs) $)^{1,2}$. These chemicals, emitted unintentionally in combustion processes, are characterized by their toxicity to humans and animals, persistence in the environment, and ability to accumulate through the food chain, as well as to their capacity to undergo long-range atmospheric transport (LRAT) ${ }^{3}$. Those properties define the chemicals known as Persistent Organic Pollutants (POPs), whose production and use have been eliminated in many countries, or restricted in the case of the PCDD/Fs, through the implementation of the Stockholm Convention protocol. The application of this protocol has meant a notable decrease in the PCDD/F environmental burdens, which has become evident not only in environmental, but also in biological monitoring 
studies worldwide ${ }^{4-6}$. However, PCDD/Fs are still widespread in the environment, as well as in the food chain $^{7,8}$. In relation to this, monitoring studies are necessary to assess the trends and to identify current sources as a way to support environmental policies. Environmental monitoring programs are common tools used to evaluate the environmental impact and health risks of pollutant sources ${ }^{9,10}$. In order to perform an effective environmental monitoring program, the selection of suitable monitors is essential. Furthermore, an accurate choice in the number of sampling sites and/or the sampling periodicity is also essential. Taking into account these factors, a wide environmental surveillance program was initially designed and implemented to control the environmental impact of the HWI of Constantí, as well as to evaluate the human health risks potentially derived from exposure to PCDD/Fs around the facility. In 1998, before the HWI started regular operations, background PCDD/F concentrations were determined in soil and vegetation samples. Since then, data have been periodically updated $^{11-13}$. According to the results obtained in the first period of the program (1998-2003), no human health risks were associated to the normal activity of the facility. However, local authorities decided to continue with the surveillance program to conduct a long-term evaluation of the potential HWI impact. Since then, concentrations of PCDD/Fs have been analyzed in soils and vegetation in subsequent years ${ }^{11,14,15}$. The most remarkable finding of the second survey (2004-2008) was the notable increase observed in PCDD/F herbage levels (2008). That increase was attributed to a difference in the rain pattern during the period before sampling. In 2009, a slight change in the design of the environmental surveillance program was performed by reducing the number of sampling points from 40 to 30 . This modification attempted to eliminate redundant information ${ }^{15}$. The current study presents novel data regarding the $\mathrm{PCDD} / \mathrm{F}$ environmental concentrations and the temporal trends found in recent years, both in herbage (2010 and 2012) and soil (2011), after the last modification of the sampling approach. In addition, factors and causes that might yield to misinterpretation when evaluating temporal trends of pollutants in environmental monitors were also analyzed, based on the results of more than 10 years of continuous surveillance. The human health risks derived from exposure to PCDD/Fs by the population living around the facility were also evaluated.

\section{Materials and methods}

\subsection{Sampling}

In April 2010 and 2012, thirty samples of vegetation (Piptatherum L.) were collected in the surroundings of the HWI of Constantí (Catalonia, Spain). The selected species is the same as that previously sampled in previous campaigns. In turn, in April 2011, soils were also sampled at different sites around the facility. A

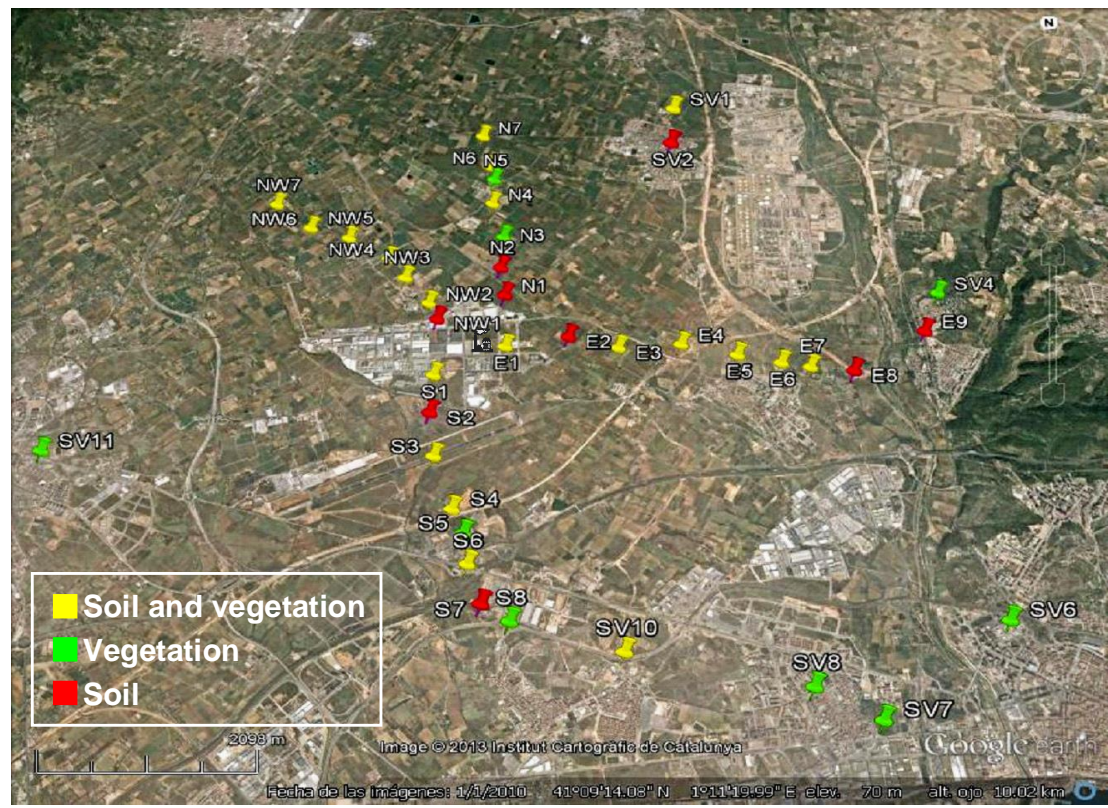

Fig.1. Area of study. 
detailed study of the initial sampling points considered in the baseline and the subsequent studies, showed that some of them had fluctuant values ${ }^{11,13,16,17}$, suggesting a potential significant impact of local sources. Consequently, the environmental monitoring program was changed by reducing the number of sampling sites from 40 to $30^{15,18,19}$. Those sites presenting especially fluctuant concentrations and/or being located near potential emission sources of $\mathrm{PCDD} / \mathrm{Fs}$, were therefore eliminated in subsequent surveys. In soils, 6 of these 10 sampling points were adjacent to roads and streets, making evident the influence of traffic as an important source of PCDD/Fs ${ }^{15}$. The sampling sites (Fig. 1) were situated within a $7-\mathrm{km}$ radius, at different distances (500, 1000, 1500, 2000, 2500, 3000, 3500, 4000, and $>4000 \mathrm{~m}$ ) and directions (east, north, northwest, and south). Approximately, $150 \mathrm{~g}$ of herbage was collected at each sampling site by cutting at a height of approximately $4 \mathrm{~cm}$ from the ground. Samples were immediately packed in aluminum foils. After arrival at the laboratory, they were dried at room temperature and packed until analysis. Surface (upper $5 \mathrm{~cm}$ ) soils were collected as bulk samples of $500 \mathrm{~g}$, representing an area of approximately $10 \mathrm{~m}^{2}$, and stored in polyethylene bags. They were also dried at room temperature and homogenized by sieving through a 2-mm mesh screen.

\subsection{Analytical procedure}

The 2,3,7,8-substituted congeners of $\mathrm{PCDD} / \mathrm{Fs}$ in soil and herbage samples were quantified by highresolution gas chromatography/high-resolution mass spectrometry (HRGC/HRMS), according to the USEPA method 1613. Approximately $40 \mathrm{~g}$ (dry weight) of soil or vegetation was used for the analysis. A mixture of ${ }^{13} \mathrm{C}_{12}$-labeled standards was added before Soxhlet extraction with toluene for a minimum of $20 \mathrm{~h}$. The extract was subsequently subjected to multilayer silica column cleanup procedure followed by microcolumns of graphitized carbon and Florisil columns. HRGC/HRMS analysis was carried out using in an Agilent 7890A gas chromatograph coupled to a Waters Autospec Premier (electron ionization and multiple ion detection mode, with resolution at 10,000). An RTX$5 \mathrm{MS}$ column was used. For detection, at least two masses $\left(\mathrm{M}^{+}\right.$and $\mathrm{M}^{2+}$, on one hand, $\mathrm{M}^{2+}$ and $\mathrm{M}^{4+}$, on the other hand) were used for each native and labeled dioxin and furan homologue group. Quantitation was performed following the isotopic dilution method.

\subsection{Data analysis}

In order to compare the current results with those of previous surveys, International Toxic Equivalents (ITEQ) were calculated using the Toxicity Equivalency Factors (TEFs) established by the North American Treaty Organisation (1988). When a PCDD/F congener level was lower than the respective detection limit, the concentration of that congener was assumed to be one half of the detection limit (ND = $1 / 2$ LOD). Data analyses were carried out using the SPSS 19.0 statistical software package. The Levene test was applied to analyze the equality of variances. A probability of $p<0.05$ was considered as statistically significant.

\section{Results and discussion}

\subsection{PCDD/F concentrations and temporal trends}

Tables 1 and 2 summarize the PCDD/F concentrations of the individual soil and herbage samples, respectively, collected around the HWI from 2010 to 2012, as well as the temporal variation (in percentage) with respect to previous studies. Information regarding the direction and distance from the HWI to the sampling points, as well as the type of sampling site (rural or urban) is also given. In turn, Fig. 2 presents the total concentrations of PCDD/Fs in soils and herbage of all the campaigns performed from the beginning of the surveillance program. In general terms, the concentrations of PCDD/Fs in soils were similar during the whole study. However, the levels found in the last two years were slightly lower than those found in the baseline (1998) study. In 1998, the concentrations of PCDD/Fs in soils ranged between 0.12 and $17.2 \mathrm{pg}$ I-TEQ/g, with median and mean values of 0.75 and $1.59 \mathrm{pg}$ I-TEQ/g, respectively ${ }^{17}$. However, if we do not consider the sampling points removed in subsequent studies, the range would be $0.12-5.11 \mathrm{pg} \mathrm{I}-\mathrm{TEQ} / \mathrm{g}$, with a mean value of $1.01 \mathrm{pg} \mathrm{I}-\mathrm{TEQ} / \mathrm{g}$. In 2009, $\mathrm{PCDD} / \mathrm{F}$ concentrations ranged between 0.09 and $2.99 \mathrm{pg}$ I$\mathrm{TEQ} / \mathrm{g}$, with median and mean levels of $0.42 \mathrm{pg} \mathrm{I}-$ TEQ/g and $0.75 \mathrm{pg}$ I-TEQ/g, respectively. In 2011, the $\mathrm{PCDD} / \mathrm{F}$ concentrations in soils ranged between 0.08 and $2.93 \mathrm{pg} \mathrm{I-TEQ/g}$, with median and mean values of 0.34 and $0.67 \mathrm{pg}$ I-TEQ/g. In the 2011 study, samples with the highest levels were those collected at the farthest sampling sites, which correspond to urban 
zones. The sampling site SV1 showed the highest concentration, with a level of $2.93 \mathrm{pg} \mathrm{I-TEQ/g.}$

Table 1. Temporal trends of PCDD/Fs (pg I-TEQ/g) in soil samples collected around the HWI of Constantí.

\begin{tabular}{|c|c|c|c|c|c|c|c|}
\hline \multirow[b]{2}{*}{ Sample } & \multirow{2}{*}{$\begin{array}{c}\text { Distance } \\
\text { to HWI } \\
\text { (m) }\end{array}$} & \multirow[b]{2}{*}{ Area } & \multirow[b]{2}{*}{$1998 *$} & \multirow[b]{2}{*}{$2009 *$} & \multirow[b]{2}{*}{2011} & \multicolumn{2}{|c|}{$\%$ variation } \\
\hline & & & & & & $\begin{array}{c}1998- \\
11\end{array}$ & $\begin{array}{c}2009- \\
11\end{array}$ \\
\hline E1 & 500 & $\mathrm{R}$ & 1.22 & 0.26 & 0.32 & -74 & 22 \\
\hline E2 & 1000 & $\mathrm{R}$ & 0.52 & 0.45 & 0.87 & 68 & 93 \\
\hline E3 & 1500 & $\mathrm{R}$ & 0.41 & 0.22 & 0.87 & 111 & 298 \\
\hline E4 & 2000 & $\mathrm{R}$ & 0.65 & 0.16 & 0.09 & -87 & -45 \\
\hline E5 & 2500 & $\mathrm{R}$ & 5.11 & 1.10 & 0.25 & -95 & -77 \\
\hline E6 & 3000 & $\mathrm{R}$ & 0.40 & 2.99 & 0.08 & -80 & -97 \\
\hline E7 & 3500 & $\mathrm{R}$ & 0.12 & 0.43 & 0.66 & 450 & 52 \\
\hline E8 & 4000 & $\mathrm{R}$ & 1.99 & 0.55 & 2.08 & 5 & 275 \\
\hline E9 & $>4000$ & $\mathrm{R}$ & 0.16 & 0.21 & 0.18 & 13 & -16 \\
\hline N1 & 500 & $\mathrm{R}$ & 0.34 & 0.22 & 0.27 & -20 & 23 \\
\hline N2 & 1000 & $\mathrm{R}$ & 0.23 & 0.21 & 0.09 & -63 & -58 \\
\hline $\mathbf{N 3}$ & 1500 & $\mathrm{R}$ & 0.26 & - & - & - & - \\
\hline N4 & 2000 & $\mathrm{R}$ & 0.75 & 0.32 & 0.28 & -62 & -10 \\
\hline N5 & 2500 & $\mathrm{R}$ & 0.13 & - & - & - & - \\
\hline N6 & 3000 & $\mathrm{R}$ & 0.51 & 0.46 & 0.14 & -73 & -70 \\
\hline N7 & 3500 & $\mathrm{R}$ & 0.60 & 1.46 & 0.22 & -63 & -85 \\
\hline NW1 & 500 & $\mathrm{R}$ & 0.64 & 0.34 & 0.36 & -44 & 5 \\
\hline NW2 & 1000 & $\mathrm{R}$ & 0.22 & 1.85 & 2.43 & 1003 & 31 \\
\hline NW3 & 1500 & $\mathrm{R}$ & 0.43 & 0.94 & 0.42 & -3 & -56 \\
\hline NW4 & 2000 & $\mathrm{R}$ & 3.68 & 1.18 & 0.42 & -89 & -64 \\
\hline NW5 & 2500 & $\mathrm{R}$ & 0.66 & 0.10 & 0.25 & -62 & 142 \\
\hline NW6 & 3000 & $\mathrm{R}$ & 1.07 & 0.87 & 0.25 & -76 & -71 \\
\hline NW7 & 3500 & $\mathrm{R}$ & 2.34 & 0.32 & 0.91 & -61 & 184 \\
\hline S1 & 500 & $\mathrm{R}$ & 1.10 & 1.82 & 0.46 & -58 & -75 \\
\hline S2 & 1000 & $\mathrm{R}$ & 1.02 & 0.24 & 0.20 & -81 & -19 \\
\hline S3 & 1500 & $\mathrm{R}$ & 0.75 & 0.41 & 0.44 & -42 & 7 \\
\hline S4 & 2000 & $\mathrm{R}$ & 0.45 & 0.09 & 0.93 & 106 & 947 \\
\hline S5 & 2500 & $\mathrm{R}$ & 1.01 & - & - & - & - \\
\hline S6 & 3000 & $\mathrm{R}$ & 1.00 & 0.19 & 0.08 & -92 & -59 \\
\hline S7 & 3500 & $\mathrm{R}$ & 0.35 & 0.27 & 0.17 & -52 & -38 \\
\hline S8 & 4000 & $\mathrm{R}$ & 1.94 & - & - & - & - \\
\hline SV1 & $>4000$ & $\mathrm{U}$ & 0.15 & 2.84 & 2.93 & 1852 & 3 \\
\hline SV2 & $>4000$ & $\mathrm{U}$ & 2.00 & 0.58 & 0.54 & -73 & -7 \\
\hline SV4 & $>4000$ & $\mathrm{U}$ & 3.43 & - & - & - & - \\
\hline SV6 & $>4000$ & $\mathrm{U}$ & 3.61 & - & - & - & - \\
\hline SV7 & $>4000$ & $\mathrm{U}$ & 2.42 & - & - & - & - \\
\hline SV8 & $>4000$ & $\mathrm{U}$ & 17.2 & - & - & - & - \\
\hline SV9 & $>4000$ & $\mathrm{U}$ & 3.06 & - & - & - & - \\
\hline SV10 & $>4000$ & $\mathrm{U}$ & 0.84 & 1.28 & 2.87 & 242 & 124 \\
\hline SV11 & $>4000$ & $\mathrm{U}$ & 0.75 & - & - & - & - \\
\hline Mean & & & 1.59 & 0.75 & 0.67 & -58 & -11 \\
\hline SD & & & 2.79 & 0.77 & 0.81 & -71 & 5 \\
\hline Median & & & 0.75 & 0.42 & 0.34 & -55 & -19 \\
\hline Min & & & 0.12 & 0.09 & 0.08 & -33 & -11 \\
\hline Max & & & 17.2 & 2.99 & 2.93 & -83 & -2 \\
\hline
\end{tabular}

R: rural; U: urban; E: east; N: north, NW: northwest; S: south; SV: urban sites at different directions. *Data from previous surveys ${ }^{14,15}$.

Comparatively, higher levels were also observed at the SV10 and NW2 sites (2.87 and $2.43 \mathrm{pg}$ I-TEQ/g, respectively). In comparison with the 2009 survey, the levels of PCDD/Fs in 2011 decreased in 14 samples, while in the other 16 sites, the concentrations increased.
Globally, this means a not statistically significant decrease in the PCDD/F soil concentrations of $20 \%$ ( $>00.05$ ). During the period 1998-2011, a global reduction of $55 \% \quad(\mathrm{p}<0.01)$ was also noted, with decreases and increases in 21 and 9 sampling sites, respectively.In the 1998 study, 2,3,7,8-TCDD (the most toxic congener) was detected in 20 of 40 soil samples, with a maximum concentration of $0.05 \mathrm{pg} / \mathrm{g}$. In the 2009 study, 2,3,7,8-TCDD was detected in 7 of 30 soil samples, with a maximum concentration of $0.08 \mathrm{pg} / \mathrm{g}$. In the present study (2011), it was detected in 8 samples (max.: $0.14 \mathrm{pg} / \mathrm{g}$ ). On the other hand, the concentration of OCDD, which was the most abundant congener, ranged 4.76-527, 1.97-449 and 2.13-608 pg/g in 1998, 2009 and 2011, respectively. OCDD was followed by 1,2,3,4,6,7,8-HpCDD and OCDF. Although soil levels in 2011 were lower than those found in 2009, PCDD/F congener profiles were similar, as the difference was only significant for a few congeners: 2,3,7,8-TCDD $(\mathrm{p}<0.001), \quad 1,2,3,7,8-\mathrm{PeCDD} \quad(\mathrm{p}<0.05), \quad 1,2,3,7,8,9-$ $\mathrm{HxCDD}(\mathrm{p}<0.001)$, and 1,2,3,4,7,8-HxCDF ( $<<0.001)$.

A clear relationship between the distance to the HWI and soil PCDD/F concentrations was not found (Fig. 3). In 2011, the highest concentrations were found at the farthest distances (>4000 m), being all of them urban samples, followed by those collected at $1000 \mathrm{~m}$. The concentrations found in urban soils were significantly higher than those in rural soils (2.01 vs. $0.44 \mathrm{pg}$ I$\mathrm{TEQ} / \mathrm{g} ; \mathrm{p}<0.05)$. This trend has been observed since the surveillance program was initiated. In urban samples, the concentrations of most PCDD/F congeners increased from 1998 to 2011, being statistically significant only for 1,2,3,4,7,8-HxCDD, 1,2,3,6,7,8-HxCDF and $2,3,4,6,7,8-\mathrm{HxCDF}(\mathrm{p}<0.05)$. On the other hand, OCDD and OCDF were the only congeners whose concentration was reduced.

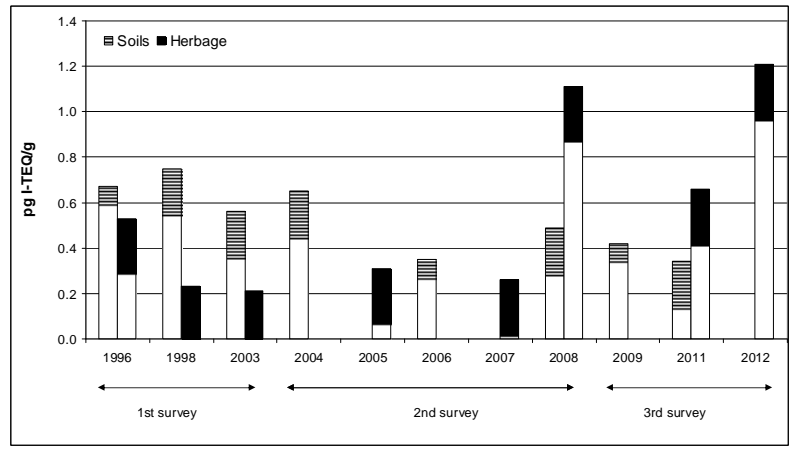

Fig. 2. Temporal trends in PCDD/F levels near the HWI. Results from 1996-2009 are published elsewhere ${ }^{13-15,17}$. 
Table 2. Temporal trends of PCDD/Fs (pg I-TEQ/g) in herbage samples collected around the HWI of Constantí.

\begin{tabular}{|c|c|c|c|c|c|c|c|c|c|}
\hline \multirow{2}{*}{ Sample } & \multirow{2}{*}{$\begin{array}{c}\text { Distance to } \\
\text { HWI (m) }\end{array}$} & \multirow{2}{*}{ Area } & \multirow{2}{*}{ 1998* } & \multirow{2}{*}{$2008 *$} & \multirow{2}{*}{2010} & \multirow{2}{*}{2012} & \multicolumn{3}{|c|}{$\%$ variation } \\
\hline & & & & & & & 1998-2012 & 2008-2012 & 2010-2012 \\
\hline E1 & 500 & $\mathrm{R}$ & 0.21 & 0.29 & 0.50 & 1.28 & 509 & 334 & 157 \\
\hline E2 & 1000 & $\mathrm{R}$ & 0.32 & 0.47 & - & - & - & - & - \\
\hline $\mathbf{E 3}$ & 1500 & $\mathrm{R}$ & 0.19 & 0.23 & 0.15 & 0.46 & 140 & 100 & 203 \\
\hline E4 & 2000 & $\mathrm{R}$ & 0.22 & 0.23 & 0.73 & 0.26 & 20 & 16 & -64 \\
\hline E5 & 2500 & $\mathrm{R}$ & 0.18 & 0.33 & 0.66 & 0.19 & 7 & -42 & -71 \\
\hline E6 & 3000 & $\mathrm{R}$ & 0.17 & 0.95 & 1.10 & 12.1 & 7018 & 1174 & 999 \\
\hline E7 & 3500 & $\mathrm{R}$ & 0.14 & 0.27 & 0.57 & 0.20 & 42 & -25 & -65 \\
\hline E8 & 4000 & $\mathrm{R}$ & 0.51 & 0.34 & - & - & - & - & - \\
\hline E9 & $>4000$ & $\mathrm{R}$ & 0.43 & 0.83 & - & - & - & - & - \\
\hline N1 & 500 & $\mathrm{R}$ & 0.25 & 0.36 & - & - & - & - & - \\
\hline N2 & 1000 & $\mathrm{R}$ & 0.19 & 0.94 & - & - & - & - & - \\
\hline N3 & 1500 & $\mathrm{R}$ & 0.24 & 1.12 & 0.50 & 0.32 & 33 & -72 & -36 \\
\hline N4 & 2000 & $\mathrm{R}$ & 0.28 & 1.53 & 1.33 & 0.59 & 111 & -61 & -55 \\
\hline N5 & 2500 & $\mathrm{R}$ & 0.30 & 0.84 & 0.57 & 2.01 & 571 & 140 & 253 \\
\hline N6 & 3000 & $\mathrm{R}$ & 0.27 & 1.22 & 0.60 & 2.01 & 645 & 66 & 233 \\
\hline N7 & 3500 & $\mathrm{R}$ & 0.19 & 1.74 & 0.71 & 1.21 & 535 & -31 & 70 \\
\hline NW1 & 500 & $\mathrm{R}$ & 0.52 & 0.24 & - & - & - & - & - \\
\hline NW2 & 1000 & $\mathrm{R}$ & 0.20 & 0.23 & 0.61 & 0.19 & -4 & -16 & -69 \\
\hline NW3 & 1500 & $\mathrm{R}$ & 0.21 & 1.20 & 0.54 & 0.45 & 114 & -63 & -17 \\
\hline NW4 & 2000 & $\mathrm{R}$ & 0.32 & 1.13 & 0.48 & 0.19 & -41 & -83 & -60 \\
\hline NW5 & 2500 & $\mathrm{R}$ & 0.32 & 0.30 & 2.93 & 0.66 & 107 & 123 & $\begin{array}{l}-77 \\
\end{array}$ \\
\hline NW6 & 3000 & $\mathrm{R}$ & 0.21 & 0.36 & 0.63 & 10.8 & 5040 & 2873 & 1613 \\
\hline NW7 & 3500 & $\mathrm{R}$ & 0.48 & 0.60 & 0.81 & 1.17 & 144 & 95 & 45 \\
\hline S1 & 500 & $\mathrm{R}$ & 0.18 & 1.39 & 0.84 & 2.00 & 1011 & 44 & 137 \\
\hline S2 & 1000 & $\mathrm{R}$ & 0.34 & 0.71 & - & - & - & - & - \\
\hline $\mathbf{S 3}$ & 1500 & $\mathrm{R}$ & 0.23 & 1.78 & 0.66 & 0.70 & 205 & -61 & 7 \\
\hline S4 & 2000 & $\mathrm{R}$ & 0.17 & 2.84 & 1.87 & 3.10 & 1726 & 9 & 66 \\
\hline S5 & 2500 & $\mathrm{R}$ & 0.19 & 3.60 & 1.01 & 1.61 & 749 & -55 & 59 \\
\hline S6 & 3000 & $\mathrm{R}$ & 0.19 & 3.28 & 0.70 & 4.00 & 2004 & 22 & 468 \\
\hline S7 & 3500 & $\mathrm{R}$ & 0.21 & 2.13 & - & - & - & - & - \\
\hline S8 & 4000 & $\mathrm{R}$ & 0.32 & 2.35 & 0.55 & 3.40 & 961 & 44 & 522 \\
\hline SV1 & $>4000$ & $\mathrm{U}$ & 0.18 & 1.25 & 0.19 & 2.17 & 1104 & 73 & 1051 \\
\hline SV2 & $>4000$ & $\mathrm{U}$ & 2.01 & 0.92 & - & - & - & - & - \\
\hline SV4 & $>4000$ & $\mathrm{U}$ & 0.17 & 2.46 & 0.31 & 1.81 & 964 & -26 & 486 \\
\hline SV6 & $>4000$ & $\mathrm{U}$ & 0.24 & 1.41 & 0.91 & 1.70 & 609 & 21 & 86 \\
\hline SV7 & $>4000$ & $\mathrm{U}$ & 0.21 & 2.36 & 2.36 & 0.81 & 287 & -66 & -66 \\
\hline SV8 & $>4000$ & $\mathrm{U}$ & 0.45 & 1.98 & 2.12 & 1.01 & 124 & -49 & -52 \\
\hline SV9 & $>4000$ & $\mathrm{U}$ & 0.32 & 3.07 & - & - & - & - & - \\
\hline SV10 & $>4000$ & $\mathrm{U}$ & 0.36 & 1.11 & 2.58 & 1.25 & 247 & 13 & -52 \\
\hline SV11 & $>4000$ & $\mathrm{U}$ & 0.25 & 2.33 & 0.45 & 1.41 & 462 & -40 & 212 \\
\hline Mean & & & 0.31 & 1.27 & 0.93 & 1.97 & 535 & 55 & 112 \\
\hline SD & & & 0.29 & 0.94 & 0.71 & 2.76 & 852 & 194 & 289 \\
\hline Median & & & 0.23 & 1.11 & 0.66 & 1.21 & 426 & 9 & 83 \\
\hline Min & & & 0.14 & 0.23 & 0.15 & 0.17 & 21 & -26 & 13 \\
\hline Max & & & 2.01 & 3.60 & 2.93 & 12.1 & 502 & 236 & 313 \\
\hline
\end{tabular}

R: rural; U: urban; E: east; N: north, NW: northwest; S: south; SV: urban sites. *Data from previous surveys ${ }^{14,15}$.

Regarding herbage, PCDD/F concentrations in 1998 ranged from 0.14 to $2.01 \mathrm{pg} \mathrm{I}-\mathrm{TEQ} / \mathrm{g}$, with a median value of $0.23 \mathrm{pg} \mathrm{I}-\mathrm{TEQ} / \mathrm{g}$ and a mean of $0.31 \mathrm{pg}$ I$\mathrm{TEQ} / \mathrm{g}$. In 2008, the $\mathrm{PCDD} / \mathrm{F}$ herbage concentrations ranged between 0.23 and $3.60 \mathrm{pg} \mathrm{I}-\mathrm{TEQ} / \mathrm{g}$, with median and mean values of 1.11 and $1.27 \mathrm{pg}$ I-TEQ/g. In 2010, the PCDD/F concentrations in herbage ranged from 0.15 to $2.93 \mathrm{pg} \mathrm{I-TEQ/g}$ with a median of $0.66 \mathrm{pg} \mathrm{I-TEQ/g}$ and a mean of $0.93 \mathrm{pg} \mathrm{I-} \mathrm{TEQ/g.} \mathrm{In} \mathrm{2012,} \mathrm{the} \mathrm{levels} \mathrm{of}$
PCDD/Fs ranged from 0.17 to $12.1 \mathrm{pg} \mathrm{I}-\mathrm{TEQ} / \mathrm{g}$, with mean and median values of 1.97 and $1.21 \mathrm{pg} \mathrm{I-TEQ/g}$, respectively. A notable increase in the total PCDD/Fs in herbage has been observed since 2008 (Fig. 3). In 2010 the PCDD/F highest concentration, $2.93 \mathrm{pg} \mathrm{I-TEQ/g,}$ was found at NW5 (rural site), followed by SV9 and SV5 (both urban sites located at a distance $>4 \mathrm{~km}$ ), with values of 2.58 and $2.36 \mathrm{pg}$ I-TEQ/g, respectively. In 2012, the highest concentrations were noted in E6 (12.1 pg I-TEQ/g) and NW6 (10.8 pg I-TEQ/g), both of them 
in rural areas. The statistical analysis of the data identified these samples as outliers. The mean PCDD/F concentrations found in herbage samples in 2010 (0.66 pg I-TEQ/g) were lower than those obtained in 2008 (1.11 pg I-TEQ/g), which was reasonable according to the high values found in 2008. However, in 2012, the mean PCDD/F levels (1.97 pg I-TEQ/g) increased again with respect to 2010 , reaching even higher mean values than those obtained in 2008 (1.27 pg I-TEQ/g). However, the difference was not significant ( $p>0.05)$. It must be highlighted that if outliers were excluded from the statistical treatment of the data, the mean PCDD/F concentration in soils would be $1.29 \mathrm{pg} \mathrm{I}-\mathrm{TEQ} / \mathrm{g}$, a very similar level to that found four years before $(1.27 \mathrm{pg} \mathrm{I-}$ TEQ/g). Between 2010 and 2012, PCDD/Fs levels in herbage increased in 18 of 30 samples, while in the remaining 12 the concentrations decreased in different degree. This meant a global increase of $83 \%$ in the median value ( $p>0.05)$. During the period 1998-2012, the global increment was $424 \%(\mathrm{p}<0.001)$, diminishing the levels of PCDD/Fs in only 2 samples and increasing in 28. When data of 2008 and 2012 were compared, $\mathrm{PCDD} / \mathrm{F}$ concentrations increased in 16 samples and decreased in 14 samples, being the global increase percentage, $8 \%(\mathrm{p}>0.05)$.

When assessing individually the PCDD/F congeners, most of them were detected in all samples. In 1998, the most toxic congener, 2,3,7,8-TCDD, presented a maximum concentration of $0.21 \mathrm{pg} / \mathrm{g}$, with a median value of $0.02 \mathrm{pg} / \mathrm{g}$. In 2008, 2,3,7,8-TCDD was detected in 13 samples, with a maximum concentration of 0.06 $\mathrm{pg} / \mathrm{g}$, and a median value of $0.03 \mathrm{pg} / \mathrm{g}$. In 2010, 2,3,7,8TCDD was detected in 16 samples, with a maximum concentration of $0.06 \mathrm{pg} / \mathrm{g}$ and a median value of 0.02 pg/g. In 2012, 2,3,7,8-TCDD was detected in 21 samples, being 0.20 and $0.03 \mathrm{pg} / \mathrm{g}$ the maximum and median values, respectively. OCDD was the predominant congener in the 1998 and 2008 surveys, while $1,2,3,4,6,7,8$-HpCDF was the main contributor in 2010 and 2012.

In general terms, a clear correlation between the distance and the levels of PCDD/Fs in herbage samples was not found (Fig. 3). In 2010, the highest concentrations were found at $>4000 \mathrm{~m}$, which was the farthest sampling distance and corresponded to urban areas. In 2012, the highest levels were noted at $3000 \mathrm{~m}$ (rural sites). Anyhow, in both cases the highest PCDD/F values were noted far from the HWI. As traffic is identified as an important emission source of PCDD/Fs ${ }^{19}$, data were also studied according to the characteristics of the zone (urban or rural) where each sampling site is located. The same tendency has been noted since the background (1998) survey, with higher PCDD/F levels in urban than in rural samples. However, the difference was only statistically significant in the first study (0.29 vs. $0.22 \mathrm{pg} \mathrm{I-TEQ/g;}<<0.05)$. In 2010, median $\mathrm{PCDD} / \mathrm{F}$ concentrations were $0.91 \mathrm{pg} \mathrm{I-TEQ} / \mathrm{g}$ in urban zones and $0.66 \mathrm{pg}$ I-TEQ/g in rural areas ( $\mathrm{p}>0.05$ ). In 2012, PCDD/F concentrations were again higher in traffic-impacted areas than in rural zones (1.41 vs. $1.17 \mathrm{pg}$ I-TEQ/g; p>0.05). Although the differences were not significant, this finding confirms that traffic is a key parameter in the environment of urban zones.
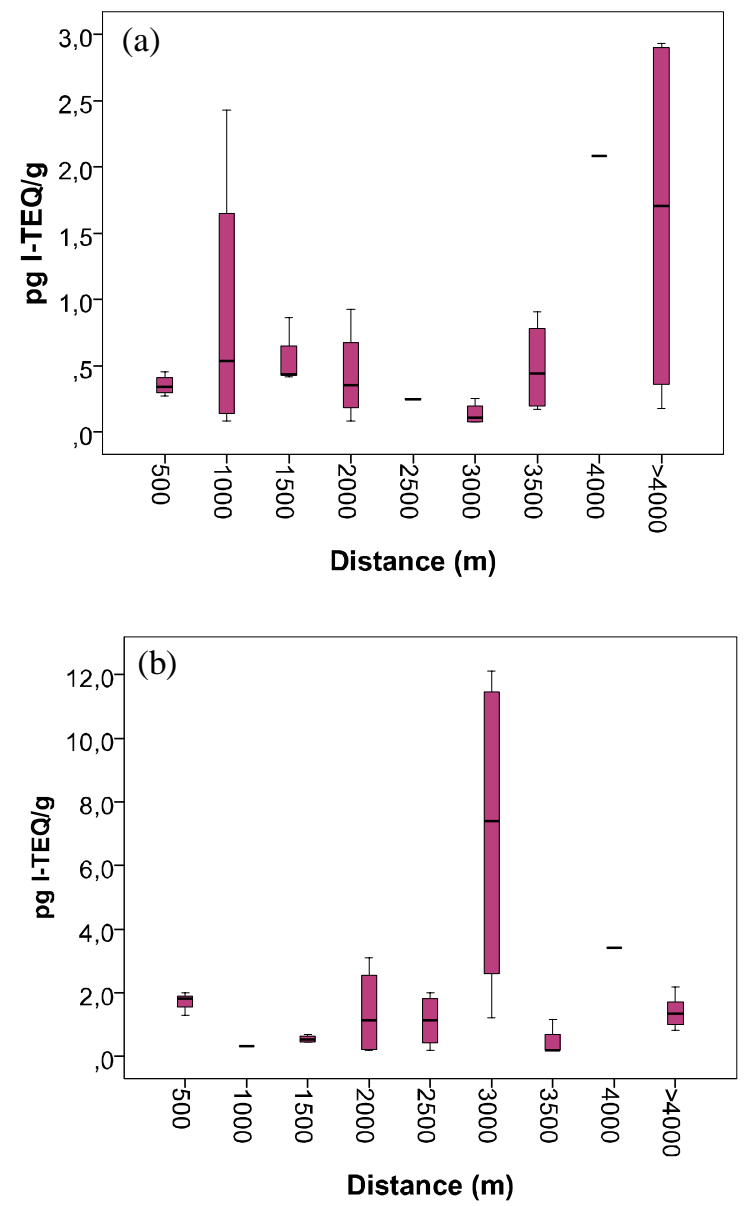

Fig. 3. Boxplots of PCDD/Fs in samples of: (a) soils and (b) herbage, according to the distance to the HWI. 


\subsection{Principal Component Analysis}

In order to evaluate the potential changes in the $\mathrm{PCDD} / \mathrm{F}$ congener profiles in herbage, in addition to the previously performed statistical analysis, a Principal Component Analysis (PCA) was performed. PCA is a very useful tool for the visualization of relationships among samples and variables in large databases. PCA was applied by using the results of all herbage samples analyzed from the baseline (1998) to the current (2012) study. The aim was: a) to determine potential differences between samples collected far and near the HWI, b) to study potential different profiles between urban and rural sites, and c) to establish potential changes in profiles through time, before and after the HWI initiated regular operations, and especially during the last sampling period when a $\mathrm{PCDD} / \mathrm{F}$ raise in vegetation was noted. The ultimate goal of applying PCA was to identify changes in the sources of $\mathrm{PCDD} / \mathrm{Fs}$, as well as the influence of the HWI on the surrounding environment. PCA provided a 2dimensional model, with 2 principal components (PC1 and PC2) explaining $76.4 \%$ and $8.5 \%$ of the variance, respectively. The score plot of PC1 vs. PC2 is depicted in Fig. 4a. Most samples clustered together, with some outliers presenting very high loadings in PC1 (E6 and NW6, in 2012) and/or PC2 (SV2 and SV8 in 1998, E6 and E8 in 2003, S5 in 2005, and SV1 in 2012). It must be remarked that those outliers: a) corresponded to different sampling periods, b) were indistinctively collected in urban and rural areas, and c) were taken at different distances. Consequently, they cannot be assumed to be associated among them. Furthermore, none of those samples were collected close to the WHI. Therefore, these profiles could be linked with specific pollutant sources. In order to examine the relationship of samples in more detail, the main cluster was zoomed (Fig. 4b), allowing the identification of different patterns with respect to the initial cluster. On one hand, the variance of the samples collected in 1998, 2003 and 2005 was mainly associated with PC2 (OCDD and $1,2,3,7,8,9-\mathrm{HxCDF})$, while the variance of the samples collected in 2008, 2010 and 2012 was essentially correlated with PC1 (penta-dioxins, hexa-dioxins, TCDF, penta-furans, and hepta-furans). Hence, the increment of total PCDD/Fs since 2008 was associated with a change in the PCDD/F congener profiles. Samples with higher loadings in PC1 were, in general, collected in the South direction and in urban sites.
However, some samples collected in other directions, such as NW5 (2010), E6 (2012) and N6 (2012) showed also high PC1 loadings. In summary, PCA did not suggest a clear correlation between PCDD/F congener profiles and the distance or the type of zone (urban/rural). However, it clearly evidenced a change in PCDD/F herbage profiles from 2008 onwards, in both urban and rural areas.
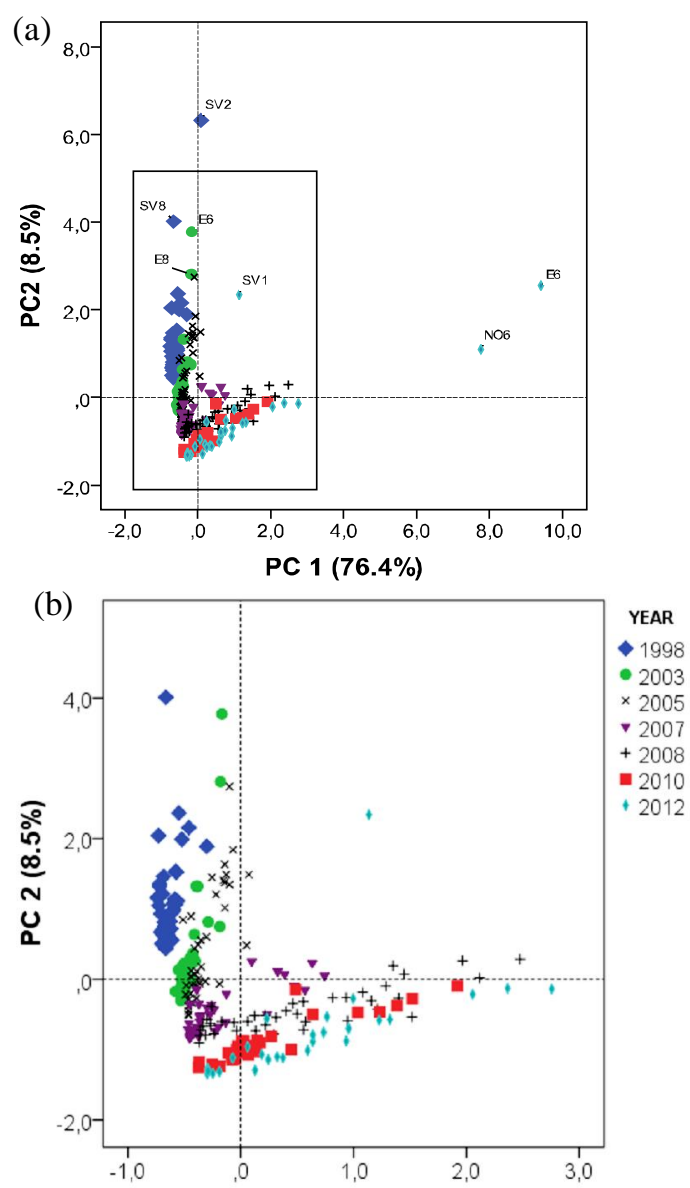

Fig. 4. PCA scatterplot of PCDD/Fs in herbage samples.

Herbage samples have been widely used as passive samplers of air of $\mathrm{PCDD} / \mathrm{Fs}$ and other semivolatile organic pollutants $(\mathrm{SVOCs})^{20,21}$. In turn, as these compounds may strongly bind to soil organic matter, soils may be considered as cumulative matrices. In consequence, soils are generally utilized as long-term monitors of SVOC pollution ${ }^{22,23}$. According to that, when those monitors are simultaneously used in environmental studies, $\mathrm{PCDD} / \mathrm{F}$ concentrations found in soils are usually higher than in herbage $\mathrm{e}^{14,24,25}$. However, 
and especially since 2008, we have been finding unexpected results regarding $\mathrm{PCDD} / \mathrm{F}$ levels in vegetation. Thus, in the most recent campaigns, herbage values were found to be higher than those in soils. Furthermore, while PCDD/Fs in soils have been progressively decreasing in soils since the baseline (1998) study, the levels in herbage increased, being this raise notable in the last period of the surveillance program (2008-2012). Those results could question the suitability of vegetation as a short-term environmental monitor.

The reasons for those surprising results may be diverse, including the real impact of the HWI and/or the impact of other local sources, changes in the environmental/meteorological conditions, or the effect of PCDD/F volatilization from soils. It is well known that different sources of PCDD/Fs are characterized by different fingerprints ${ }^{26-28}$. Therefore, changes in the emission sources would entail variations in ambient profiles. As above-mentioned, the variation of the total concentrations and profiles of PCDD/Fs in herbage was detected in 2008, 9 years after the HWI had started its regular operations. In addition, the increment of PCDD/Fs was observed in vegetation samples collected irrespectively of the distance to the plant. This would suggest that the HWI was not the main cause of those changes. Although PCDD/F congener profiles in the gas stack and vegetation could be compared to infer the contribution of emissions in the environmental burdens, this approach would be incorrect. Profiles of PCDD/Fs in herbage samples are dependent not only on ambient air profiles, but also in the air-plant transfer process. This is dependent on the physicalï chemical properties of each one of the congeners, as well as on a number of environmental variables (temperature, rainfall, solar radiation, etc). Since similar profiles were observed near and far sampling sites from the HWI, it was originally assumed that these variations in $\mathrm{PCDD} / \mathrm{F}$ herbage profiles and levels could be reasonably due to different rainfall patterns and/or other meteorological variables for each sampling period. Precipitation in the 2008 survey was the most critical parameter, as higher $\mathrm{PCDD} / \mathrm{F}$ levels were linked with an extremely dry spring $^{15}$. Figure 5 depicts the total concentrations of PCDD/Fs together with the precipitation during March, the month previous to the samplings, for the period 2005-2010. Unexpectedly, although the 2010 and 2012 campaigns presented higher rainfall, PCDD/F concentrations continued increasing. Consequently, the increment of PCDD/Fs seems to be independent on the rainfall. With regard to the effect of volatilization from soil, vegetation receives inputs of airborne organic contaminants via gas-phase deposition, particulate dry deposition, and wet deposition. In vegetation, the accumulation of SVOCs varies depending on the leaf morphology and wax content, while in soils, the amount of organic matter is the key parameter. However, pollutants may also desorb from soil and pollute the air or vegetation. $\mathrm{PCDD} / \mathrm{F}$ uptake from air to leaves is mainly responsible for contamination of aerial plant parts $^{29}$. Volatilization of PCDD/Fs from soils occurs through vapor phase diffusion ${ }^{30}$. As volatilization is controlled by the Henryôs constant ${ }^{31}$, this determines the extent to which this process is restricted by the air boundary layer. It has been reported that OCDD does not vaporize under environmental conditions, deriving in long half-lives in soils ${ }^{31}$. TCDD will volatilize most rapidly from soils in summer months, while in winter, volatilization rates will be minor. In the present case, the mean temperature of March 2012, the previous month of sampling, was $11.4 \pm 1.6^{\circ} \mathrm{C}$ during the whole study. It involves low temperature variability, and therefore, low probability of volatilization as the cause of this PCDD/F increase. In summary, according to the recent $\mathrm{PCDD} / \mathrm{F}$ herbage results, it could be speculated that new $\mathrm{PCDD} / \mathrm{F}$ emission sources are affecting the area under evaluation. However, this is not reflected in recent ambient air monitoring studies in the same area ${ }^{32}$. Consequently, herbage should be reconsidered as a viable short-term monitor to measure $\mathrm{PCDD} / \mathrm{Fs}$, while the consistency of these data should be supported by levels detected in other environmental matrices.

Emission air was also periodically monitored, and the $\mathrm{PCDD} / \mathrm{F}$ congener profiles in gas stack were compared with that relative to soils and vegetation. The emission profile, dominated by $1,2,3,4,6,7,8-\mathrm{HpCDF}$, is absolutely different from that in soil samples. Furthermore, although this congener was also found in relatively higher concentrations in herbage, its contribution percentage with respect to the total was much minor with respect to that in gas stack. This lack of similarity in the PCDD/F congener profiles of different environmental matrix, evidenced in previous studies $^{26}$, confirms the small influence of the HWI emissions of PCDD/Fs on the environment. 


\subsection{Human health risks}

The environmental concentrations of $\mathrm{PCDD} / \mathrm{Fs}$ were used to assess the health risks for the population living around the HWI. PCDD/F exposure was divided into two pathways: environmental (direct) and dietary (indirect). To calculate environmental exposure, three routes were considered: inhalation, dermal absorption, and soil ingestion ${ }^{33,34}$. Detailed expressions have been given elsewhere ${ }^{35}$. Airborne PCDD/F levels were obtained from a recent investigation in the same area ${ }^{32}$. The health risks for an adult population are presented in Table 3. The total mean environmental exposure to $\mathrm{PCDD} / \mathrm{Fs}$ was $5.04 \cdot 10^{-6} \mathrm{ng} \mathrm{I-TEQ} / \mathrm{kg} /$ day, being air inhalation the main contributor $(57 \%)$. In turn, the contribution of dermal contact and soil ingestion was much lower.

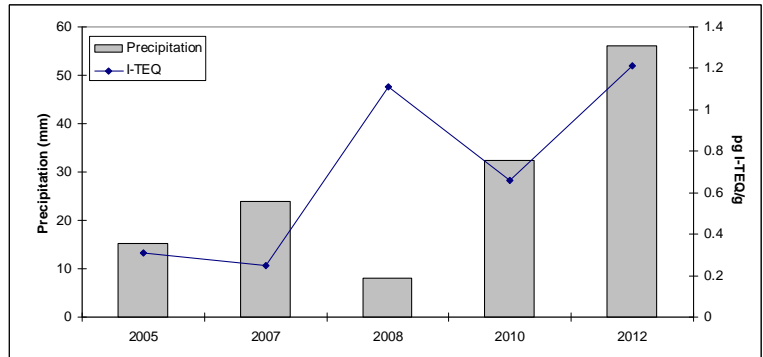

Fig. 5. PCDD/F levels around the HWI vs. rainfall.

Data regarding dietary exposure $\left(4.73 \cdot 10^{-6} \mathrm{ng} \mathrm{I}\right.$ $\mathrm{TEQ} / \mathrm{kg} / \mathrm{day}$ ) was obtained from a recent study in the same region ${ }^{8}$. Food intake was estimated as the main pathway of exposure to $\mathrm{PCDD} / \mathrm{Fs}$, contributing $99 \%$ to the total exposure. These results are in accordance with previous studies where diet has been demonstrated to be the main exposure pathway of $\mathrm{PCDD} / \mathrm{Fs}^{36}$. The noncarcinogenic risk, expressed as hazard quotient (HQ), was calculated by comparing the total exposure and the TCDD reference dose ${ }^{37}$. The HQ was $2.41 \cdot 10^{-3}$, which is far lower than the unity, considered as the safe limit. The carcinogenic risk was calculated by multiplying the total exposure by the oral slope factor for PCDD/Fs. The total carcinogenic risk was $2.84 \cdot 10^{-6}$, which is also below the threshold level $\left(10^{-5}\right)$ according to the Spanish regulation.

In conclusion, the evaluation of the $\mathrm{PCDD} / \mathrm{F}$ concentrations measured around the HWI of Constantí shows that PCDD/Fs in soils have been decreasing from the baseline study. In turn, notable fluctuations have been observed in vegetation in the course of the surveillance program, with an increasing trend since 2008. Data analysis performed evaluating distances, site types and profiles, shows that this increase is not associated with the HWI emissions of PCDD/Fs. In any case, it can be concluded that, to avoid any misinterpretation, the use of herbage as environmental monitor should be always analyzed together with other environmental monitors. The results of the human health risk assessment indicate that the current PCDD/F levels do not mean unacceptable health risks according to national and international regulations. Notwithstanding, the continuous monitoring is still recommended, especially taking into account the notable fluctuations observed in herbage. Adding other monitors, such as air, in the surveillance program is strongly recommended to guarantee the reliability in the conclusions.

Table 3. Environmental and dietary exposure to PCDD/Fs for adults living near the HWI of Constantí, Spain.

\begin{tabular}{|c|c|}
\hline \multicolumn{2}{|l|}{ Environmental concentrations } \\
\hline Mean PCDD/F concentration in soil (ng I-TEQ/kg) & $6.70 \mathrm{E}-01$ \\
\hline Mean PCDD/F concentration in air $\left(\mathrm{ng} \mathrm{I}-\mathrm{TEQ} / \mathrm{m}^{3}\right)$ & $1.05 \mathrm{E}-05$ \\
\hline \multicolumn{2}{|l|}{ Environmental exposure } \\
\hline Soil ingestion (ng TEQ/kg/day) & $1.04 \mathrm{E}-06$ \\
\hline Dermal contact (ng TEQ/kg/day) & $1.12 \mathrm{E}-06$ \\
\hline Air inhalation (ng TEQ/kg/day) & $2.88 \mathrm{E}-06$ \\
\hline Total environmental exposure (ng TEQ/kg/day) & $5.04 \mathrm{E}-06$ \\
\hline Dietary exposure (ng TEQ/kg/day) & $4.73 \mathrm{E}-04$ \\
\hline Total exposure ( $\mathrm{ng} T E Q / \mathrm{kg} /$ day) & $4.78 \mathrm{E}-04$ \\
\hline
\end{tabular}

\section{Acknowledgments}

This study was financially supported by the Agència de Residus de Catalunya, Generalitat de Catalunya, Barcelona, Catalonia, Spain.

\section{References}

1. H. Gao, Y. Ni, H. Zhang, L. Zhao, N. Zhang, X. Zhang, Q. Zhang and J. Chen, Stack gas emissions of PCDD/Fs from hospital waste incinerators in China, Chemosphere 77 (2009) 634-6392.

2. M. Mari and J. L. Domingo, Toxic emissions from crematories: A review, Environ. Int. 36 (2010) 131-137.

3. A. Schecter, L. Birnbaum, J. J. Ryan and J. D. Constable, Dioxins: An overview, Environ. Res. 101 (2006) 419-428. 
4. M. Mari, M. Nadal, M. Schuhmacher and J. L. Domingo, Body burden monitoring of dioxins and other organic substances in workers at a hazardous waste incinerator, Int. J. Hyg. Environ. Health in press (2013) doi: 10.1016/j.ijheh.2013.01.003.

5. K. L. Sundqvist, M. Tysklind, P. Geladi, I. Cato and K. Wiberg, Congener fingerprints of tetra- through octachlorinated dibenzo- $p$-dioxins and dibenzofurans in Baltic surface sediments and their relations to potential sources, Chemosphere 77 (2009) 612-620.

6. S. Salihovic, E. Lampa, G. Lindström, L. Lind, P. M. Lind and B. van Bavel, Circulating levels of Persistent Organic Pollutants (POPs) among elderly men and women from Sweden: Results from the Prospective Investigation of the Vasculature in Uppsala Seniors (PIVUS), Environ. Int. 44 (2012) 59-67.

7. A. Passuello, M. Mari, M. Nadal, M. Schuhmacher and J. L. Domingo, POP accumulation in the food chain: Integrated risk model for sewage sludge application in agricultural soils, Environ. Int. 36 (2010) 577-583.

8. J. L. Domingo, G. Perelló, M. Nadal and M. Schuhmacher, Dietary intake of polychlorinated dibenzo- $p$-dioxins and dibenzofurans (PCDD/Fs) by a population living in the vicinity of a hazardous waste incinerator: assessment of the temporal trend. Environ. Int. 50 (2012) 22-30.

9. A. K. M. Rafique Ahammed and B. M. Nixon, Environmental impact monitoring in the EIA process of South Australia, Environ. Impact Assess. Rev. 26 (2006) 426-447.

10. Y. Bai, H. Niu and X. Wen, The strategy study on the development and innovations of Chinese environmental monitoring: A comparison study, Proced. Environ. Sci. 13 (2012) 2458-2463.

11. N. Ferré-Huguet, M. Nadal, M. Schuhmacher and J. L. Domingo, Environmental impact and human health risks of polychlorinated dibenzo- $p$-dioxins and dibenzofurans in the vicinity of a new hazardous waste incinerator: a case study, Environ. Sci. Technol. 40 (2006) 61-66.

12. M. Nadal, A. Bocio, M. Schuhmacher and J. L. Domingo, Trends in the levels of metals in soils and vegetation samples collected near a hazardous waste incinerator Arch. Environ. Contam. Toxicol. 49 (2005) 290-298.

13. M. Schuhmacher, S. Granero, J. M. Llobet, H. A. M. de Kok and J. L. Domingo, Assessment of baseline levels of $\mathrm{PCDD} / \mathrm{F}$ in soils in the neighbourhood of a new hazardous waste incinerator in Catalonia, Spain, Chemosphere 35 (1997) 1947-1958.

14. M. Mari, M. Nadal, N. Ferré-Huguet, M. Schuhmacher, M. Borrajo and J. Domingo, Monitoring PCDD/Fs in soil and herbage samples collected near a hazardous waste incinerator. Health risks for the population living nearby, Hum. Ecol. Risk Assess. 13 (2007) 1255-1270.

15. L. Vilavert, M. Nadal, M. Mari, M. Schuhmacher and J. L. Domingo, Monitoring temporal trends in environmental levels of polychlorinated dibenzo- $p$ - dioxins and dibenzofurans: results from a 10-year surveillance program of a hazardous waste incinerator, Arch. Environ. Contam. Toxicol. 59 (2010) 521 ï 531.

16. J. L. Domingo, M. C. Agramunt, M. Nadal, M. Schuhmacher and J. Corbella, Health risk assessment of PCDD/PCDF exposure for the population living in the vicinity of a municipal waste incinerator, Arch. Environ. Contam. Toxicol. 43 (2002) 461-465.

17. M. Schuhmacher, M. C. Agramunt, M. C. RodriguezLarena, J. Díaz-Ferrero and J. L. Domingo, Baseline levels of PCDD/Fs in soil and herbage samples collected in the vicinity of a new hazardous waste incinerator in Catalonia, Spain, Chemosphere 46 (2002) 1343-1350.

18. L. Vilavert, M. Nadal, M. Schuhmacher and J. L. Domingo, Concentrations of metals in soils in the neighborhood of a hazardous waste incinerator: Assessment of the temporal trends, Biol. Trace Elem. Res. 149 (2012) 435-442.

19. J. Giné Bordonaba, L. Vilavert, M. Nadal, M. Schuhmacher, J. L. Domingo, Monitoring environmental levels of trace elements near a hazardous waste incinerator human health risks after a decade of regular operations, Biol. Trace Elem. Res. 144 (2011) 14191429.

20. F. Tian, J. Chen, X. Qiao, X. Cai, P. Yang, Z. Wang and D. Wang, Source identification of PCDD/Fs and PCBs in pine (Cedrus deodara) needles: A case study in Dalian, China, Atmos. Environ. 42 (2008) 4769-4777.

21. 21. W. Levy, B. Henkelmann, G. Pfister, M. Kirchner, G. Jakobi, A. Niklaus, J. Kotalik, S. Bernhöft, N. Fischer and K. W. Schramm, Monitoring of PCDD/Fs in a mountain forest by means of active and passive sampling, Environ. Res. 105 (2007) 300-306.

22. J. L. Domingo, S. Granero and M. Schuhmacher, Congener profiles of PCDD/Fs in soil and vegetation samples collected near to a municipal waste incinerator, Chemosphere 43 (2001) 517-524.

23. J.E. Oh, S.D. Choi, S.J. Lee and Y.S. Chang, Influence of a municipal solid waste incinerator on ambient air and soil PCDD/Fs levels, Chemosphere 64 (2006) 579-587.

24. M. Schuhmacher, M. C. Agramunt, A. Bocio, J. L. Domingo and H. A. M. de Kok, Annual variation in the levels of metals and PCDD/PCDFs in soil and herbage samples collected near a cement plant, Environ. Int. 29 (2003) 415-421.

25. M. Schuhmacher and J. L. Domingo, Long-term study of environmental levels of dioxins and furans in the vicinity of a municipal solid waste incinerator, Environ. Int. 32 (2006) 397-404.

26. M. Mari, M. Nadal, M. Schuhmacher and J. L. Domingo, Application of self-organizing maps for $\mathrm{PCDD} / \mathrm{F}$ pattern recognition of environmental and biological samples to evaluate the impact of a hazardous waste incinerator, Environ. Sci. Technol. 44 (2010) 3162-3168.

27. M. Mari, M. Nadal, M. Schuhmacher and J. L. Domingo, Monitoring PCDD/Fs, PCBs and metals in the 
ambient air of an industrial area of Catalonia, Spain, Chemosphere 73 (2008) 990-998.

28. R. J. Wenning, M. A. Harris, B. Finley, D. J. Paustenbach and H. Bedbury, Application of pattern recognition techniques to evaluate polychlorinated dibenzo-p-dioxin and dibenzofuran distributions in surficial sediments from the lower Passaic River and Newark Bay, Ecotoxicol. Environ. Saf. 25 (1993) 103125.

29. European Commission, Compilation of EU Dioxin Exposure and Health Data, Task 3 ï Environmental Fate and Transport. DG Environment. AEA Technology, Oxford, UK. Available at http://ec.europa.eu/environment/dioxin/pdf/task3annex.p df, (1999). Accessed: April 17, 2013.

30. R. Freeman and J. Schroy, Environmental mobility of dioxins. In: Aquatic Toxicology and Hazard Assessment: Eighth symposium. ASTM Special Technical Publication 891. ASTM publication code number (PCN) 04-891000-16 (1984).

31. S. R. Wild and K. C. Jones, Organic chemicals entering agricultural soils in sewage sludges: screening for their potential to transfer to crop plants and livestock, Sci. Total Environ. 119 (1992) 85-119.

32. L. Vilavert, M. Nadal, M. Schuhmacher and J. L. Domingo, Long-term monitoring of dioxins and furans near a municipal solid waste incinerator: human health risks, Waste Manage. Res. 30 (2012) 908-916.

33. J. Rovira, M. Mari, M. Nadal, M. Schuhmacher and J. L. Domingo, Environmental monitoring of metals, PCDD/Fs and PCBs as a complementary tool of biological surveillance to assess human health risks, Chemosphere 80 (2010) 1183-1189.

34. J. Rovira, M. Mari, M. Schuhmacher, M. Nadal and J. L. Domingo, Environmental pollution and human health risks near a hazardous waste landfill. Temporal trends, $J$. Risk Anal. Crisis Response 2 (2012) 13-20.

35. J. Rovira, V. Linares, M. Bellés, M. Nadal and J. L. Domingo, Airborne levels of uranium in the surroundings of various industrial facilities: Human health risks, J. Risk Anal. Crisis Response 1 (2011) 4247.

36. G. Perelló, J. Gómez-Catalán, V. Castell, J. M. Llobet and J. L. Domingo, Assessment of the temporal trend of the dietary exposure to PCDD/Fs and PCBs in Catalonia, over Spain: Health risks, Food Chem. Toxicol. 50 (2012) 399-408.

37. U.S. EPA, Preliminary Remediation Goals. U.S. Environmental Protection Agency. Available at: http://www.epa.gov/region9/superfund/prg (2011). Accessed: April 17, 2013. 